\title{
The Correlation between the Number of Tourists and the Number of Nights Spent in the Hotel: Analysis Indicator of Hotel Business Efficiency
}

\author{
Despa Radu ${ }^{1}$, Catalin Huidumac ${ }^{2}$, Nicoleta Dumitru Rossela ${ }^{1}$ and Negricea Costel ${ }^{1}$ \\ ${ }^{1}$ Romanian-American University \\ ${ }^{2}$ Academy of Economic Studies
}

\begin{abstract}
:
The aim of a travel agency reorientation was to create tourist packages for tourism business. Consequently, the travel agency intended to study the image of a hotel " $\mathrm{H}$ " in Bucharest Romania, regarding its tourism activity effectiveness, considering that the hotel is subject to a law of general objectives for improving efficiency. The tourist activity is considered to be independent and this activity, and in particular the tourist movement, are reflected by the evolution of two indicators: the number of tourists' arrivals and the number of nights spent in the hotel, these having a significant impact on the efficiency. The analysis of business efficiency based on the correlation between the number of tourists who come to the hotel and the number of nights spent, is the best way of getting ahead of results and achieving an appropriate level of tourists.
\end{abstract}

Keywords: efficiency, business hotel, correlation, tourists, nights spent in hotel

\section{Introduction}

In a research project, a tourism agency is considering for the next period a shift in the direction of the business of creating travel packages for rural tourism, and tourism business, considering that the impact of economic crisis on the behavior of potential tourists will be significantly in the future.

In the direction of creating tour packages tourism business has pursued research picture of a hotel " $H$ " in Bucharest, having as starting point the work efficiency of the tourist hotel. Economic efficiency in the hotel is particularly complex because the result of expressing a range of activities aimed primarily services: accommodation, tourist transport, services etc..

Agency would like to outline packages and, in relation to the study results, given the characteristics of tourism services offered by the hotel, unless they contribute to overcoming the expectations, to increase its business efficiency.

Effectiveness analysis of results obtained by determining the correlation between the number of tourists arrivals and spent, is only part of the study on the effectiveness of the business hotel «H».

\section{The efficiency of the business tourist hotel}

Economic efficiency of the business travel hotel is particularly complex because the result of expressing a range of activities: accommodation services, tourist transport, additional services, international tourism, etc.. Tourist hotel is subject to the condition which is essential to achieve good results and meet an appropriate level of the tourists. General pattern of activity efficiency tourist hotel is shaping the relationship between the results obtained Copyright (C) 2010 Despa Radu, Catalin Huidumac Nicoleta Dumitru Rossela, Negricea Costel . This is an open access article distributed under the Creative Commons Attribution License unported 3.0, which permits unrestricted use, distribution, and reproduction in any medium, provided that original work is properly cited. Contact Author: Despa Radu, e-mail: radudespa@ yahoo.com 
in the work and expenses. It is a resourceconsuming part, on the other hand, producing effects.

In this context, economic efficiency and fixed at the level of tourist hotel answer how resources are used, because the links are complex, and the economic aspect is closely linked to the social.

\section{Analysis of correlation between the number of tourists arrived and nights spent for the hotel «H»}

Hotel «H» 3-star accommodation capacity of 183 places in 88 rooms of various types as: rooms with 1 bed (ST1), rooms with 1 Queen Size bed (STQ); rooms with 2 beds (ST2 ) rooms with 1 King Size bed (Sup) Junior Suite (Sup) and Flat (flat).

Among the facilities available to the location or are placed near them, we mention: Bar / lounge, Casino, Reception and room service 24h, Express Checkout, Meeting facilities / Banquets, conference rooms, Business center, Parking, Shops / Services Commercial, Restaurant, Rent a car, Swimming pool, fitness center and tennis, Transport on request etc.. Service offers of hotel «H» is addressed to highincome clientele. For this reason most tourists are foreign nationality.

Because the practice of relatively high rates for a $3 *$ hotel, but also by offering services to the highest standards, and the hotel has formed a very good hotel market in Bucharest.

Due to high standards it has imposed hotel «H», competition must be viewed in terms of market share which it is addressed. But very important is that the hotel market in Bucharest is no strong competition consists of many hotels $3 *$ or $4 *$.

In order to maintain market position, the hotel «H» offers a wide range of free services or pay in particular tourism business. He also created programs to customer loyalty: FLAVOURS and AMBASADOR CLUB, by which customers get various benefits (free early check in, late check out free rooms at promotional rates or even free). Problems standing on the hotel to them relating to increased quality, the competitiveness of services offered to increase the efficiency of business travel hotel. Efficiency trends in the evolution of business travel hotel " $\mathrm{H}$ are outlined and the results obtained through an analysis of the connection and interdependence between the number of tourists and business hotel spent corresponding period in January 2006 December 2008. Data on the number of tourists arrivals and the corresponding spent are taken from the quarters unit hotel under investigation.

Information on the number of tourists arrivals and the corresponding spent are collected quarterly by the hotel subject to the research. The trend of increasing arrivals of tourists in the hotel «H» is evidenced both by the graphical representation, and the results obtained by the calculation of indicators, absolute, relative and average.

Following analysis of data collected we find that the evolution of the number of tourists over the first quarter of 2006, taken as the reference quarter, was a positive, because negative values in absolute changes.

Thus the greatest difference between the number of tourists in a quarter versus the first quarter of 2006 was 2290 persons, in the IV th quarter of 2007, representing an increase of 3.7 times ie $270 \%$. If we analyze the evolution of the number of tourists, namely the changes that occur from one quarter to another, we find that the greatest increase took place in quarter II of 2006 before the first quarter of that year, registering a increase of 956 persons with a rate of $113 \%$. You can also see in column 4 of table that the largest change in effect was negative in the first quarter of 2008, compared to fourth quarter of century of 2007, registering a decrease of 523 tourists, ie decreased by $17 \%$. It was established during the quarterly period 2006-2008 an average increase by about 163 tourists per quarter, an average increase of 1.1 times with an average rate of $11 \%$ tourists per quarter, according to the arrival of establishing a quarterly average of about 2253 tourists. 


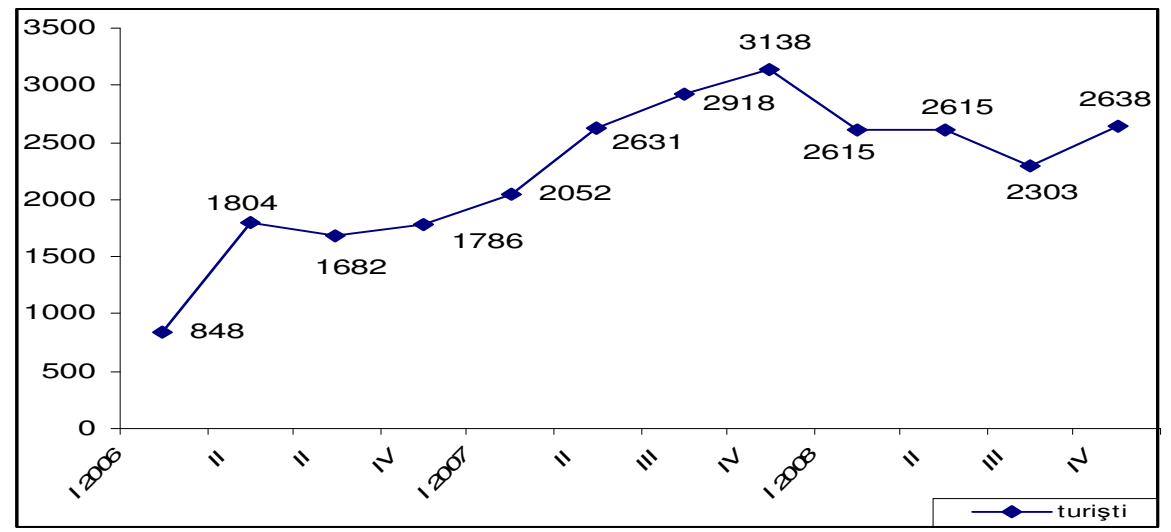

Figure 1. Evolution of the number of tourists

The second important indicator used in the analysis of tourist movement number is nights spent. Determination of absolute and relative indicators to determine the number of nights spent developments, led to the following conclusions:

- compared to first quarter of 2006 is a significant increase in each quarter of the number of nights spent. The highest growth recorded in the third quarter century of 2007 with an addition of 5423 spent, a creștre of 4.19 times with a rate of $319 \%$.

- if started with the first half of 2006 the hotel had a continuously grow, from a semester to an other, nights spent the situation from one month to another is as follows:
- largest increase occurred in quarter II of 2006 face the first quarter of that year spent in 2564, so by 2.51 times, with a rate $151 \%$ and the lowest quarter of 2007 III girl of the same quarter of the year with an increase of only 85 spent, with a growth rate of $1 \%$.

- the most significant decrease was recorded in the first quarter of 2008 compared to last quarter of 2007 spent -1372 , with a rate of $-19 \%$ and the smallest decrease in the second quarter versus the first quarter of 2008 -- 66 spent, a rate of $-1 \%$.

Calculation of average indicators led to a growth area, spent about 361 / quarter, i.e. $16 \%$ effective in determining the conditions spent an average of approximately 5656 spent quarterly.

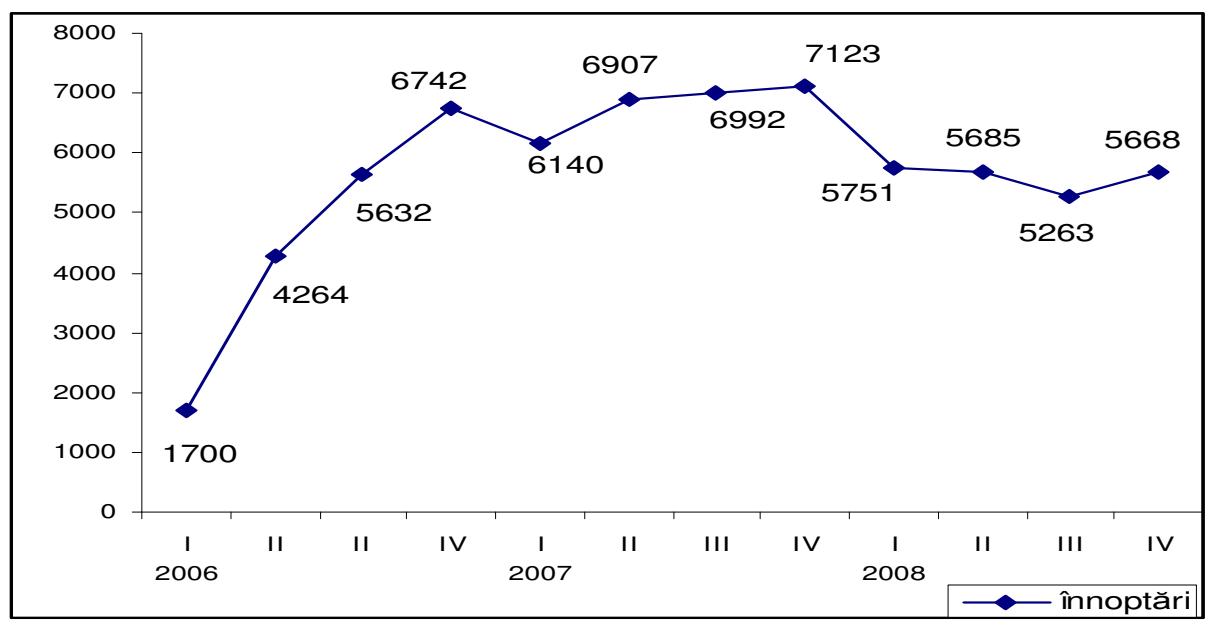

Figure 2. Evolution of number nights spent 
Correlation between number and number of tourists spent in the hotel for "H", was analyzed by the method of correlation and regression. Using the two methods for determining and measuring the correlations between the two indicators, with implications for the interpretation of results to establish effective business hotel, is considering a graphic representation to determine the trend and direction of their addiction.

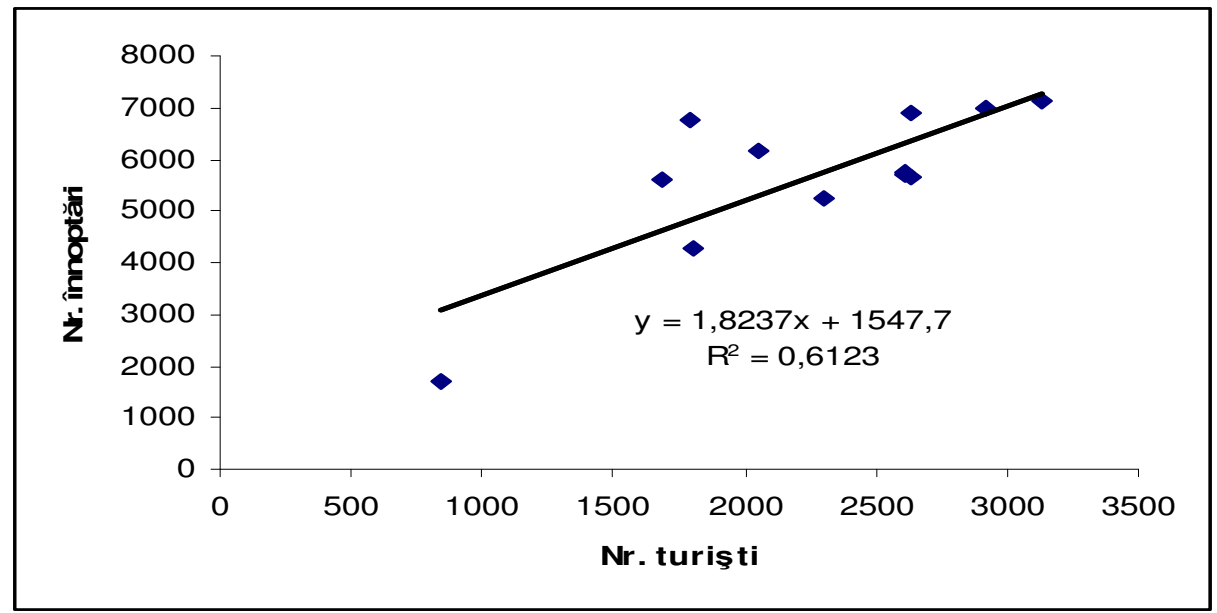

Figure 3 Correlation between the numbers tourists end the spent

The graphical representation suggests that the number of tourists and spent a direct correlation with a certain tendency to linearity. Applying the method of correlation parameters assumed the correlation coefficient, whose value of 0.78 we show the existence of a direct link, between the tourists and the spent. With the increasing number of tourists is a significant increase in the number of and spent, the trend established for the two indicators are almost proportional.

Using the regression method requires an estimate of regression function parameters, achieved through the method of least squares.

On the basis of the 12 quarters of the years 2006-2008, results of which interpretation is presented below, as follows:

Table 1.

\begin{tabular}{ll} 
Regression Statistics & \\
\hline Multiple R & 0,7824764 \\
R Square & 0,6122693 \\
Adjusted R Square & 0,5734962 \\
Standard Error & 977,99007 \\
Observations & 12 \\
\hline
\end{tabular}

The value of the correlation (0.78), confirms the existence of strong direct link between the two indicators and look indicates linearity direct link between the number of tourists and spent, the result is the same as the correlation coefficient.
Influence on the number of tourists spent is $61.23 \%$, as confirmed by the coefficient of determined, the remaining $38.77 \%$ being other factors going on, random, accidental. 
Table 2

\begin{tabular}{|l|l|l|l|l|l|l|}
\hline & Coefficients & $\begin{array}{l}\text { Standard } \\
\text { Error }\end{array}$ & t Stat & P-value & $\begin{array}{l}\text { Lower } \\
95 \%\end{array}$ & $\begin{array}{l}\text { Upper } \\
95 \%\end{array}$ \\
\hline Intercept & 1547,73 & 1071,59 & 1,446 & 0,1792 & $-839,93$ & 3935,39 \\
\hline $\begin{array}{l}\text { Tourist } \\
\text { number }\end{array}$ & 1,82 & 0,46 & 3,98 & 0,0026 & 0,80 & 2,85 \\
\hline
\end{tabular}

The equation of linear adjustment theory $\hat{y}=\hat{a}+\hat{b} x_{i}$, by using it in studying the link between the two indicators becomes:

$$
\hat{y}_{i}=1547,73+1,82 x_{i}
$$

Regression coefficient $=1.82$ shows that an increase in the number of tourists at a tourist person, recorded an average increase of about 2 spent (1.82). Resulting value by test " $t$ " Student: $t_{\text {calculate }}=5.11332$
$(\mathrm{P}$-value $=0.0037)$ shows that there is no significant difference between the two indicators whose connection has been considered. This statement is supported by results on the extension of the results (lower $=0.80$ and upper $=2.85$ ), which leads to the conclusion that this correlation coefficient is determined statistically significant.

Table 3

\begin{tabular}{llllll}
\hline ANOVA & $d f$ & $S S$ & $M S$ & $F$ & Significance $F$ \\
\hline Regression & 1 & 15103625 & 15103625 & 15,79 & 0,0026 \\
Residual & 10 & 9564645,8 & 956464,58 & & \\
Total & 11 & 24668271 & & & \\
\hline
\end{tabular}

The result of using the Fisher test: $\mathrm{F}=$ 15.79 (Significance $F=0.0026<0.05$ ), we show that linear regression model used expresses very well established correlation between the number of tourists and the hotel spent corresponding " $\mathrm{H}$ " in 20062008.

Validation of the model creates the possibility of economic analysis efficiency work carried out by the hotel. Correlation obtained between the number of tourists arrived and spent is the result of policy adopted and followed the hotel " $\mathrm{H}$ ", as regards the efficiency of work. Each stage carried out during the tourist offer of a targeted implementation strategy of the business efficiency hotel.

Submission procedures for determining the degree of efficiency of business hotel "H" which reflects the built and guided the tourism unit during performance of its work:

- economic efficiency, expressed by the ratio of revenue obtained and the amounts spent to conduct business hotel, is very important collection per day per tourist, taking the trend to mitigate season providing tourism services, which should be in the spotlight of the hotel, as a condition of increasing economic efficiency;

- social efficiency, which is linked to the intake hotel facilities with materials, training in a large number of tourists from domestic and international, to spent several days especially that relates primarily to conduct a tourism business;

- promotional effectiveness, to the image that the consumer-tourist and a form of tourist offer of the hotel from the stay occurred. Departure impressions with great tourist hotel in "H" leads to the formation of the feedback to propagate through the promotion of tourism product with effective promotional effect.

- technical efficiency, which seeks solutions to the constructive and aimed at equipping technical reflect actual functionality own installations and facilities.

In the hotel business development, management, establishment and endorsed a system of indicators to reflect the efficiency of providing tourism services. Given the effort and the use thereof, may be 
noted that the main indicators which was based on evaluation of hotel «H»: the total expenditure of work accommodation, salary funds, the available capacity, and the service revenue benefits from the hotel, the benefits of additional net income, profits, etc..

\section{Conclusions on the effectiveness of a tourist hotel business under investigation}

Regardless of the method used to set and showed that, overall, the period 2006-2008 at the hotel under investigation, the two indicators: the number of tourists spent and has evolved into a close correlation, which outlines the favorable trend of the business.

The complexity of tourism product offered, modeled on the prevailing forms of tourism: tourism, business and transit, outlined the possibilities of diversification of tourist packages to achieve the efficiency of the hotel business travel research subject.

Modeling complex work efficiency of the tourist hotel should consider a number of other elements which highlights: the structure of the results and the structural changes that have occurred during the computation compared to the previous period.

Competitive advantage is obtained from the hotel when the economic environment allows the rapid accumulation of capital and specialized skills, a better transmission of information, a clearer understanding of needs and production processes. All this causes the hotel to innovate and invest, it was double the gain. The existence of a highly competitive environment is the safeguard progress on the economic scale and the imposition of global markets.

\section{References:}

[1] Despa R., Zirra D., Avrigeanu A., Munteanu A.C., Efficiency investments, the University Publishing House, Bucharest, 2005

[2] Caraiani P., Solomon A., Despa R. Applied Econometrics, University Publishing House, Bucharest, 2008;

[3] Huidumac C. Macroeconomics, Ed. Didactica and Pedagogical, Bucharest, 2002; 